\title{
Heterogeneous Parking Market Subject to Parking Rationing
}

\author{
Saeed Asadi Bagloee ${ }^{1}$ and Mohsen Asadi ${ }^{2}$ \\ ${ }^{1}$ Institute of Transport Studies, Department of Civil Engineering, Monash University, Room 126, Building 69, Wellington Road, \\ Clayton, VIC 3800, Australia \\ ${ }^{2}$ Civil Engineering Department, Kharazmi University, Tehran 15719-14911, Iran
}

Correspondence should be addressed to Saeed Asadi Bagloee; saeedasadibagloee@yahoo.com

Received 3 September 2015; Revised 10 November 2015; Accepted 12 November 2015

Academic Editor: Evangelos J. Sapountzakis

Copyright (C) 2015 S. Asadi Bagloee and M. Asadi. This is an open access article distributed under the Creative Commons Attribution License, which permits unrestricted use, distribution, and reproduction in any medium, provided the original work is properly cited.

\begin{abstract}
Different types of drivers and parking spaces delineate a heterogeneous parking market for which the literature has yet to provide a model applicable to the real world. The main obstacle is computational complexities of considering various parking restrictions along with traffic congestion on the road network. In this study, the heterogeneity aspects are considered within a Logit parking choice model. A mathematical programming problem was introduced to explicitly consider parking capacities and parking rationing constraints. The parking rationing is defined as any arrangement to reserve parking space for some specific demand such as parking permit, private parking, VIP parking, and different parking durations. Introduction of parking rationing in the presence of other constraints is a unique factor in this study which makes the model more realistic. The algorithm was tested on a central business district case study. The results prove that the algorithm is able to converge rapidly. Among the algorithm's output are shadow prices of the parking capacity and parking rationing constraints. The shadow prices contain important information which is key to addressing a variety of parking issues, such as the location of parking shortages, identification of fair parking charges, viability of parking permits, and the size of reserved parking.
\end{abstract}

\section{Introduction}

System operators are challenged by parking related problems such as parking shortages, parking demand forecasting, parking pricing, and numerous other issues. In addition, parking management has been seen as an effective measure to streamline traffic circulation [1]. Answers to these questions require a parking model for which the literature has yet to provide a reliable model applicable to large-size real networks. The attempts to model parking can be classified into nonnetwork approaches and network-based approach $[2,3]$. In a nonnetwork approach, largely through random utility theory, factors contributing to the drivers' decision to choose a parking space are investigated. Neither congestion nor parking capacity is explicitly considered in the nonnetwork approaches. In the network-based approaches, parking lots are coded as network elements. This makes the parking demand subjected to congestion impacts, yet the parking lot capacity must be addressed. This deficiency is rooted in the computational complexities of considering parking capacity simultaneously with traffic congestion on the road network. Parking availability is one of the most important factors in trip making process that can affect commuters' choices of travel mode, route, and departure time [4].

Furthermore, the importance of tradable parking permit to alleviate parking shortage in the $\mathrm{CBD}$ has been recently highlighted [5-8] for which one has to take the heterogeneity facets of the market into analysis. Like any other market, there are two parties involved: supplier (parking spaces) and consumers (drivers); as such, there exist different types of them which are needed to be considered in the parking modeling process.

In this study we combine network with nonnetwork methods to achieve a better approach, while explicitly including parking capacity subject to heterogeneous parking spaces and drivers. In the nonnetwork approaches, Logit modelsemployed for capturing drivers' parking choice behaviorswere widely used. It is evident that the choices are subject 
to parking availability, which is not explicitly considered in the parking choice models. The availability of parking is the outcome of drivers' competition to choose the best parking locations. Whenever the notion of competition appears, it implies a mathematical programming (optimization) problem [9]. Therefore, in this study, we place all the drivers with their preferences for suitable parking spaces (i.e., Logit models) into competition for available and appropriate parking spaces. Inclusion of Logit model enables us to take heterogeneous aspects of the parking in both ends (i.e., drivers and parking spaces) into account. As the literature clearly indicates, drivers consider a variety of factors when choosing a parking space, such as driving time, congestion level around the destination, and searching time for a space. Drive and parking haunting times both add extra load on traffic congestion and in the meantime both are also affected by the traffic congestion. Therefore, the parking choice Logit models must accommodate driving and parking haunting times as factors contributing to the choice utilities. By doing so, network congestion is implicitly considered. (The travel time to arrive at and park in the respective parking zones is embedded in the utility functions. Travel time is the result of congestion level. By doing so, the congestion impacts are implicitly covered in our methodology. In fact, this methodology can be coded as a module to be run once a traffic assignment is carried out in which the congestions are comprehensively taken into account and travel times are known. This is exactly what we did in our first paper [10] for the network of Abu Dhabi.)

With respect to parking supply, we introduce two sets of constraints which provide a more realistic model: (i) parking occupancy cannot exceed the capacity of parking lots; let us call it parking capacity constraint (PCC); (ii) some parking spaces may have been assigned to serve specific demand such as VIP parking space, parking permits, different parking duration (short term, long terms), disabled parking, and private parking lots; let us call this category of constraints parking rationing constraint (PRC). Some studies have addressed the former constraint (PCC) $[8,10-17]$. Considering the latter PRC constraint in the presence of the PCC constraint is a unique feature of this study.

The picture described above results in a Logit-based mathematical programming problem with two sets of constraints: PCC and PRC. The advantages of this formulation are as follows: (i) it explicitly takes the parking capacity constraints and reserved parking rationing into consideration; this brings the model closer to reality; (ii) there exists a plethora of studies concerned with the ways drivers choose parking-spaces in the form of Logit models. Even some cities have developed Logit parking choice models as part of their transportation models [15, 18-24]; by integrating Logit parking choice models in our methodology, we directly exploit the knowledge accumulated in the literature or in the cities' transportation models; (iii) the heterogeneous features of the drivers and parking spaces can be considered in the logit models.

We will test the methodology on an artificial but largesize CBD case. (In early stages of the authors' quest in parking studies, we applied a preliminary version of the current methodology to the real and large-size network of Abu
Dhabi, the capital city of United Arab Emirates (UAE) (please see [10]). Now, in the current paper, instead of again employing the case of Abu Dhabi, we consciously developed a "large-size" and stochastically made network to offer a benchmark case to the literature. This large-size network has been tabulated succinctly in this paper with all the necessary information such that it can be easily regenerated by scholars to be used in their studies. Such benchmarks are not unprecedented in transportation literatures. The famous one is the artificial network of Sioux-Falls that appeared in the literature in 1970s, and it is still being used and referred to by the scholars.) The numerical results will then be analyzed. The results show that the methodology can be applied to largesizes networks and it can address a variety of parking related inquiries.

In Section 2 we review relevant literature. The problem is described and formulated in Section 3. We lay out the algorithm of the methodology in Section 4. Section 5 is dedicated to numerical results. Finally Section 6 concludes the paper.

\section{Literature Review}

In this section we are interested in the extent to which past studies considered four issues: (i) parking capacity, (ii) parking rationing (iii), traffic congestion, and (iv) models' practical application. It is difficult to find a model in the literature that covers all four issues in one way or another [25-27]. In the nonnetwork approaches, the capacity of parking and traffic congestion can, at best, only be considered implicitly as explanatory variables in the utility functions $[22,24]$. Recent network-based approaches distinguish themselves from their older peers in terms of significant advances in their mathematical basis. Sattayhatewa and Smith Jr. [17] developed a synchronized model for traffic assignment and parking choice with parking capacity explicitly considered. Synchronizing parking choice and traffic assignment means that parking choice is explicitly subject to traffic congestion. There are a number of parameters that must be calibrated by a "maximum likelihood" method, which is time-consuming. Hence, the application of their model to real-size cases has yet to be addressed.

Arnott and Inci [11] provide an economic approach to parking pricing with both parking capacity and congestion being explicitly considered. The main problem with this method is that off-street parking capacity is not considered.

Li et al. [16] developed a joint model for mode choice, traffic assignment, and parking choice with parking and road capacity considered explicitly. Concerns about calibrating too many parameters and the practicality of application to real-size cases are not addressed. Consideration of road capacity constraint in the user-equilibrium traffic assignment may violate Wardrop's first principle which says: everybody chooses the shortest path. Consider a simple example with two paths $\mathrm{A}$ and $\mathrm{B}$ and demand of 2 users. The shortest path is A whose capacity is 1 user while B has no capacity constraint. It is evident that half of the demand would take the shortest path (A) while the others would take a longer path due to restriction in the capacity of the shortest path. This is a major 
drawback in their study and has to be addressed by adjusting the Wardrop principles [28-30].

Li et al. [31] developed a bilevel formulation for dynamic parking pricing and parking supply. Computational time required for the bi-level problem still is a concern. In addition, the outputs for both parking cost and supply are continuous numbers which are policies not easily implemented in the real world.

Zhang et al. [32] considered parking capacity using the concepts of queue theory. Zhang et al. [8] and Qian et al. [33] also explicitly considered parking capacity. Application to real-size cases has yet to be addressed.

It has been reported that a capacity constraint parking model was developed for the city of London, UK [15]. The model consists of Logit parking choice models for which the parking capacity is explicitly considered.

Some studies have adopted a microview on the parking modeling on how the individual car searches for parking spaces. These are called microsimulation or agentbased models. The main problem with the microsimulation approach is that the computation time that makes their use limited to small-size cases $[26,34]$. There are a huge number of parameters needing calibration involved in such models. The calibration requires costly and time consuming surveys to determine specific driver behavior in the area.

Recently Liu et al. [6] developed a bimodal traffic equilibrium subject to the impact of the parking spaces constraint. For simplicity, all parking spaces were inexplicitly assumed to have identical features and numerical results have yet to be shown. In the conclusion they highlighted some knowledge gaps to be further studied which are quoted as follows: "For further research, it would be interesting to take into account differentiated parking, that is, the considered parking spaces may have different parking fees, and different distances to the destination. In this case, the commuters' incentive or willingness to compete for parking spaces of different types would be different, which is a reflection of commuters' different valuations on the differentiated parking spaces. Besides, parking fees might be utilized as an instrument for managing traffic." The aforementioned knowledge gaps are precisely what is addressed in this study.

Moreover the literature review reveals that no attempt has been made to address the parking rationing issue. In some cases, ignoring or loosening parking rationing constraints cannot be tolerable. For example, consider a central business district in which the towers and skyscrapers provide a large share of the parking supply (private parking). Furthermore it is a common practice to ration the parking spaces to different parking duration demand (short term, long terms). With respect to the other issues of interest, parking capacity, traffic congestion, and practical application, there are some studies that developed robust mathematical methods to consider parking capacity and congestion explicitly. However, the mathematical complexity underlying them has hindered the practicality of applying them to real-size cases.

In this study we compromise explicit consideration of congestion to address the other three issues. In our model, traffic congestion is implicitly included as an explanatory variable within the parking utility function, while parking capacity and rationing are explicitly considered. We tested our methodology using a large-size case study.

\section{The Problem of Parking Modelling}

Let $G_{p q}$ be auto travel demand from origin $p \in P$ to destination $q \in Q$ which has to find a parking space $k \in K$. Here $G_{p q}$ is an exogenously determined parking demand too. People drive from $p$ to $k$, where they park and walk to $q$. Note that $P, Q$, and $K$ represent traffic analysis zones and parking zones, respectively. A group of proximate parking spaces can be viewed as a parking zone, which can be any type of parking including on-street parking spaces, an underground parking facility, a surface facility, or even a multistory parking structure. The drivers $\left(G_{p q}\right)$ traveling from $p$ to $q$ will park at an available parking space in lot $k$ that provides maximum utility. Utility is the core concept of discrete choice models, including Logit models. Parking cost, walking distance to the destination, security of the parking lot, being covered, as well as flow-dependent characteristics such as drive access time and time spent searching for a parking space are the most important factors that determine the utility of the parking lot. Utilities are usually defined as a linear function of the important factors contributing to choice, and this equation is called the utility function. The factors' coefficients indicate the relative importance of each factor in the utility function.

The utility of a parking space $k \in K$ is perceived by the driver. Drivers, depending on their socioeconomic characteristics, perceive different levels of utility from the same parking space. For instance, wealthy drivers have less concern about parking cost than less wealthy drivers. Therefore, we denote the utility function as $u_{p k}$ which is a function of parking $k$ as well as driver $p$. (Note that the disaggregation level of this study is not at individual levels; rather it is at zonal level. It is due to the fact that our current methodology is a macro model. Therefore the heterogeneity has been set at zonal level. In traffic modeling a zonal structure must be homogenous [35]; i.e., a zone must represent fairly similar travelers in terms of their traffic behaviors and socioeconomic characteristics. While travelers inside a zone are homogenous, they may differ from those who belong to other zones; it is called heterogeneity. Consequently, " $p$ " captures such heterogeneity between the zones.)

Regardless of any availability of parking (no capacity constraint, no rationing), the Logit parking choice model may be formulated as follows:

LPC: Logit parking choice:

$$
g_{p k q}=G_{p q} \cdot \frac{e^{u_{p k}}}{\sum_{k} e^{u_{p k}}}
$$

where $g_{p k q}$ is the number of drivers from $p$ to $q$ out of the total number of drivers $G_{p q}$ who would likely park in parking zone $k$. In fact index $k$ represents conditions of the respective parking area and the surrounding area including destination zone $q$. Hence index $q$ is dropped from utility function in (1).

Constraints for parking capacity and parking rationing are introduced here: 
PCC: parking capacity constraints:

$$
\sum_{p q} g_{p k q} \leq C_{k} \quad k \in K
$$

PRC: parking rationing constraints:

$$
\sum_{p} g_{p k q} \leq F_{k q} \quad k \in K
$$

In (2) we make sure that total parking occupation $\left(\sum_{p q} g_{p k q}\right)$ will not exceed the capacity of parking zone $\left(C_{k}\right)$. It is evident that $C_{k}$ is the available parking spaces (excluding the already occupied parking spaces). Let us call those whose destination is zone $q$ visitors to building $q$. In (3), parking zone $k$ is rationed. Accordingly, the maximum spaces in parking zone $k$ dedicated to visitors to building $q$ are $F_{k q}$. Special parking restrictions such as private parking spaces, VIP parking spaces, disabled parking, and different parking duration may be implemented by adjusting appropriate rates for $F_{k q}$. For example, if parking zone $k^{\prime}$ is private parking for building $q^{\prime}$, we can assign $F_{k^{\prime} q^{\prime}}=\infty$ and $F_{k^{\prime} q}=0 \mid q \in Q-\left\{q^{\prime}\right\}$. Simply put, the parking modeling is converted to solving the following: LPC subject to PCC and PRC (or (1) s.t. (2) and (3)).

Figure 1 is a graphic illustration of the problem structure. The primary output is $g_{p k q}$, how many cars out of $G_{p q}$ have parked at parking zone $k$. The inputs of the problem are summarized as follows:

$G_{p q}:$ number of autos driving from origin $p$ to destination $q$.

$u_{p k}:$ utility of parking $k$ perceived by drivers $p$.

$C_{k}$ : capacity of or maximum available parking spaces at parking zone $k$.

$F_{k q}$ : parking rationing; maximum parking spaces of parking zone $k$ dedicated to zone $q$.

\section{Methodology}

4.1. Logit-Based Mathematical Programming for Parking Modeling. Spiess [36] was the first scholar to solve the above problem without the parking rationing constraints. By applying the Kuhn-Tucker optimality conditions [37], Spiess [36] proved that the problem of (1) s.t. (2) is equivalent to the following minimization problem:

$$
\begin{aligned}
\operatorname{Min} & \sum_{p k q} g_{p k q}\left(\log g_{p k q}-1+u_{p k}\right) \\
\text { s.t.: } & \sum_{k} g_{p k q}=G_{p q} \quad p \in P, q \in Q .
\end{aligned}
$$

Spiess [36] then added PCC (2) to the above problem. Thus, the Logit parking choice (LPC) problem considering explicit parking capacity constraint (PCC) became as follows:
Spiess problem:

$$
\begin{array}{ll}
\text { Min } & \sum_{p k q} g_{p k q}\left(\log g_{p k q}-1+u_{p k}\right) \\
\text { s.t.: } & \sum_{k} g_{p k q}=G_{p q} \quad p \in P, q \in Q \\
& \sum_{p q} g_{p k q} \leq C_{k} \quad k \in K .
\end{array}
$$

We call the above problem ((5), (6), and (7)) the Spiess problem. Equation (6) ensures that the outcome $\left(g_{p k q}\right)$ meets the demand $\left(G_{p q}\right)$. Equation (7) is the parking capacity constraint (PCC).

It is required to ensure the feasibility of the solutions to the Spiess problem, by providing parking spaces to serve the entire demand as follows:

$$
\sum_{p q} G_{p q} \leq \sum_{k} C_{k}
$$

Clearly, in case of a parking shortage, we can assume a dummy parking zone with infinite capacity and minimum utility. Minimum utility of the dummy parking zone ensures that the dummy parking zones will not receive any car unless all the other parking spaces are occupied. Since (8) can be treated beforehand, it was excluded from the formulation of the Spiess problem. Fewer constraints make the problem more tractable.

The Spiess problem can be extended to accommodate parking rationing constraints (PRC) as follows:

parking modeling, PM, problem:

$$
\begin{array}{ll}
\text { Min } & \sum_{p k q} g_{p k q}\left(\log g_{p k q}-1+u_{p k}\right) \\
\text { s.t.: } & \sum_{k} g_{p k q}=G_{p q} \quad p \in P, q \in Q \\
& \sum_{p q} g_{p k q} \leq C_{k} \quad k \in K \\
& \sum_{p} g_{p k q} \leq F_{k q} \quad q \in Q, k \in K .
\end{array}
$$

We call the above problem the parking modeling (PM) problem. The presence of PRC (12) in the above problem leads to a feasibility discussion similar to the Spiess problem. Ensuring the feasibility of the PM problem solutions requires providing adequate rationing rates $\left(F_{k q}\right)$ with respect to available parking capacity $\left(C_{k}\right)$ and also meeting the entire demand $\left(G_{p q}\right)$ as follows:

$$
\begin{aligned}
C_{k} & \leq \sum_{q} F_{k q} \quad k \in K, \\
\sum_{p} G_{p q} & \leq \sum_{k} F_{k q} \quad q \in Q .
\end{aligned}
$$

Similarly we can ensure the feasibility of the solution beforehand by providing a dummy parking zone $k^{\prime}$ with infinite 


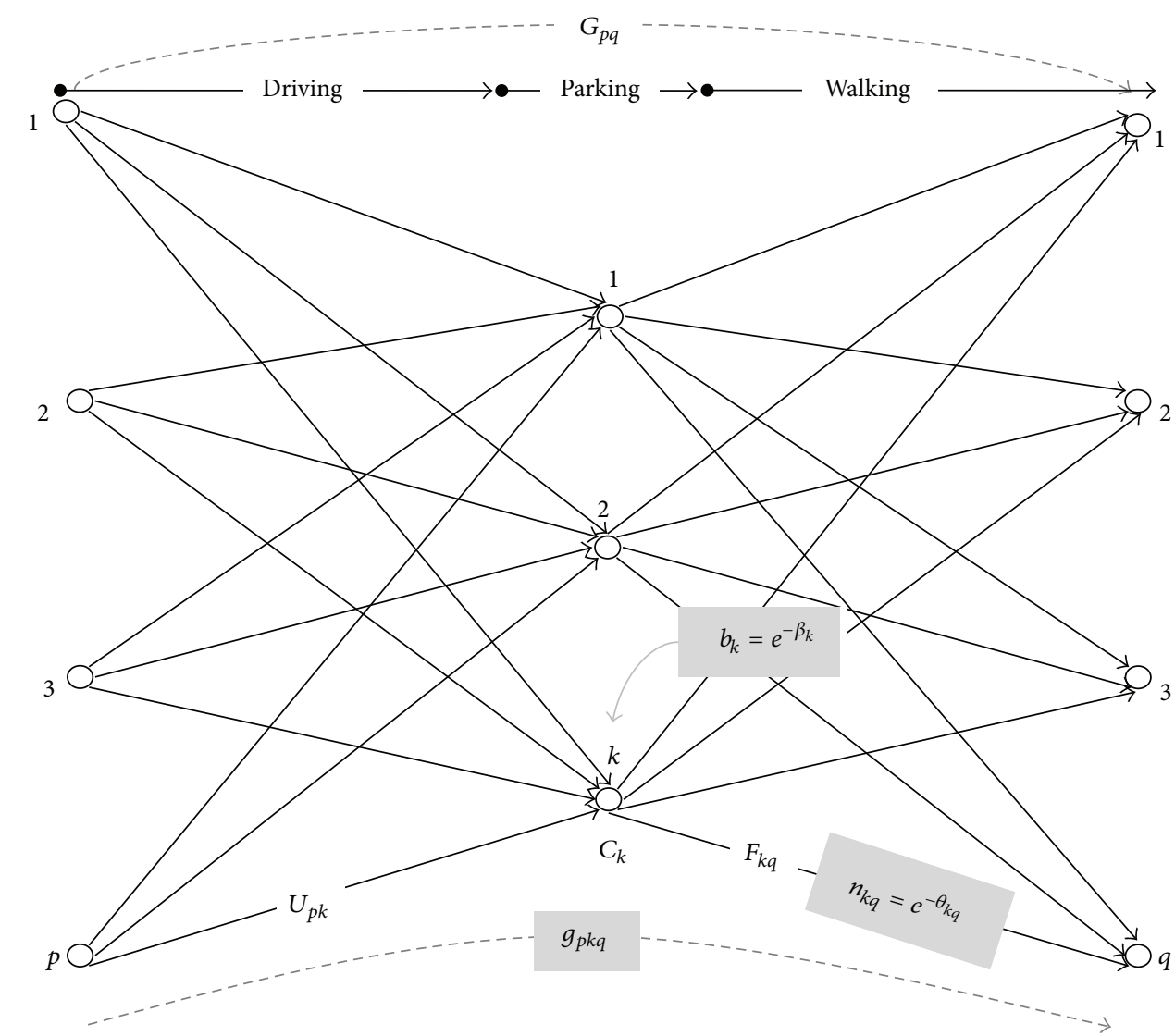

Inputs

$G_{p q}$ : demand; number of cars from origin $p$ who have to find a parking lot near destination $q$

$U_{p k}$ : utility of parking lot $k$ perceived by drivers from origin $p$ in exponential format or $U_{p k}=\exp \left(-u_{p k}\right)$

$C_{k}$ : capacity of parking zone $k$

$F_{k q}$ : parking rationing, maximum parking spaces of parking zone $k$ dedicated to drivers of destination $q$

\section{Outputs}

$g_{p k q}$ : parking flow, how many drivers from origin $p$ parked at parking $k$ and walked to destination $q$

$\beta_{k}$ : shadow price corresponding to supplied capacity at parking zone $k$

$\theta_{k}$ : shadow price corresponding to rationed capacity at parking zone $k$ for drivers of destination $q$

FIGURE 1: Structure, inputs, and outputs of the of parking modeling.

capacity $\left(C_{k^{\prime}}=\infty\right)$ and minimum utility $\left(u_{p k^{\prime}}<\min \left\{u_{p k} \mid\right.\right.$ $\left.\left.p \in P, k \in K-\left\{k^{\prime}\right\}\right\}\right)$ with no rationing $\left(F_{k^{\prime} q}=\infty \mid q \in Q\right)$. It is evident that to avoid problems of degeneracy we assume $C_{k}>0 \mid \forall k \in K$.

4.2. Solution Algorithm. We now turn our attention to establishing a solution algorithm for the PM problem. All the constraints in the PM problem are linear. Hence we can eliminate the constraint (for a more tractable problem) by deriving the dual format of the problem. To do so, let us introduce the dual variables $\alpha_{p q}$ for constraint (10) and $\beta_{k} \geq 0$ and $\theta_{k q} \geq 0$ for constrains (11) and (12), respectively. The Kuhn-Tucker optimality condition is established as follows:

$$
\begin{aligned}
L= & \sum_{p k q} g_{p k q}\left(\log g_{p k q}-1+u_{p k}\right) \\
& +\alpha_{p q}\left(\sum_{k} g_{p k q}-G_{p q}\right)+\beta_{k}\left(\sum_{p q} g_{p k q}-C_{k}\right)
\end{aligned}
$$

$$
+\theta_{k q}\left(\sum_{p} g_{p k q}-F_{k q}\right) .
$$

Hence first-order Kuhn-Tucker optimality conditions may be written as

$$
\begin{aligned}
\nabla L_{g_{p k q}}= & 0 \\
\qquad & \log g_{p k q}-1+u_{p k}+g_{p k q} \cdot \frac{1}{g_{p k q}}+\alpha_{p q} \\
& \quad+\beta_{k}+\theta_{k q}=0 .
\end{aligned}
$$

Subjecting the parking flow $\left(g_{p k q}\right)$ derived from (15) to the constraints of the PM problem ((10), (11), and (12)) results in a new problem as follows:

$$
g_{p k q}=e^{-u_{p k}-\alpha_{p q}-\beta_{k}-\theta_{k q}}
$$


Now we can establish the dual format of PM problem as follows:

$$
\begin{gathered}
D=\min _{\alpha \beta \theta} \sum_{p k q} e^{-u_{p k}-\alpha_{p q}-\beta_{k}-\theta_{k q}}+\sum_{p q} \alpha_{p q} G_{p q}+\sum_{k} \beta_{k} C_{k} \\
+\sum_{k} \theta_{k q} F_{k q}
\end{gathered}
$$

$$
\text { s.t. } \beta_{k} \geq 0, k \in K, \theta_{k q} \geq 0, k \in K, q \in Q \text {. }
$$

Again by establishing first-order Kuhn-Tucker optimality conditions for the dual problem we have

$$
\begin{array}{rl}
\nabla D_{\alpha_{p q}} & =0 \\
& \Longrightarrow \sum_{k} e^{-u_{p k}-\alpha_{p q}-\beta_{k}-\theta_{k q}}=G_{p q} \quad p \in P, q \in Q \\
\nabla D_{\beta_{k}} & 0 \\
& \Longrightarrow \sum_{p q} e^{-u_{p k}-\alpha_{p q}-\beta_{k}-\theta_{k q}} \leq C_{k} \quad k \in K \\
\nabla D_{\theta_{k q}} & 0 \\
& \Longrightarrow \sum_{p} e^{-u_{p k}-\alpha_{p q}-\beta_{k}-\theta_{k q}} \leq F_{k q} \quad p \in P .
\end{array}
$$

Solving the above equations yields optimal values of the dual variables.

Spiess [36] developed a solution algorithm using a Successive Coordinate Descent (SCD) method for his own dual problem based on the following argument: the dual problem was free of any explicit constraints; therefore it could be solved by using an SCD method. The same argument is applied to our own dual problem (17). Therefore, we developed a solution algorithm based on the SCD method as will be discussed below.

To reduce computational complexity, we eliminate the exponential terms in the optimality conditions (18) through some simple substitutions: $a_{p q}=e^{-\alpha_{p q}}, b_{k}=e^{-\beta_{k}}, n_{k q}=e^{-\theta_{k q}}$, and $U_{p k}=e^{-u_{p k}}$. Hence the nonnegativity conditions of the dual variables become $\left(a_{p q} \geq 0\right)$ and $\left(0 \leq b_{k}, n_{k q} \leq 1\right)$. Now the optimality condition of the dual problem can be rewritten as

$$
\begin{aligned}
& \sum_{k} U_{p k} \cdot a_{p q} \cdot b_{k} \cdot n_{k q}=G_{p q} \quad p \in P, q \in Q \\
& \sum_{p q} U_{p k} \cdot a_{p q} \cdot b_{k} \cdot n_{k q} \leq C_{k} \quad k \in K \\
& \sum_{p} U_{p k} \cdot a_{p q} \cdot b_{k} \cdot n_{k q} \leq F_{k q} \quad p \in P .
\end{aligned}
$$

The SCD is an iterative process and at the end of each iteration $\left(a_{p q}^{i}, b_{k}^{i}, n_{k q}^{i}\right)$ the values of the dual variables $\left(a_{p q}, b_{k}, n_{k q}\right)$ are updated for the next iteration denoted by $i$. The maximum number of iterations is denoted by $i_{\max }$. Now the SCD algorithm of the dual problem (17) can be written as follows.

Step 0 (initialization and preparation). Set $i=1$ and $a_{p q}^{0}=$ $b_{k}^{0}=n_{k q}^{0}=1$.

Step 1 (computation)

$$
\begin{aligned}
a_{p q}^{i} & =\frac{G_{p q}}{\sum_{k} U_{p k} \cdot a_{p q} \cdot b_{k} \cdot n_{k q}}, \\
g_{p k q}^{i} & =U_{p k} \cdot a_{p q}^{i} \cdot b_{k}^{i-1} \cdot n_{k q}^{i-1} .
\end{aligned}
$$

Step 2 (stopping criteria). If $\left|\sum_{p q} g_{p k q}^{i}-C_{k}\right| \leq \varepsilon_{k}$ and $\left|\sum_{p} g_{p k q}-F_{k q}\right| \leq \varepsilon_{k q}$ or $i=i_{\max }$ then Stop.

Step 3 (updating)

$$
\begin{gathered}
b_{k}^{i}=\min \left\{1, \frac{b_{k}^{i-1} \cdot C_{k}}{\sum_{p q} g_{p k q}^{i}}\right\}, \\
n_{k q}^{i}=\min \left\{1, \frac{n_{k q}^{i-1} \cdot F_{k q}}{\sum_{p} g_{p k q}^{i}}\right\} .
\end{gathered}
$$

Step 4 (continue). Set $i=i+1$ and continue to Step 1 .

The above algorithm is simple and can be encoded by any language. We used the Visual Basic (VB) language. To simplify the code's use, the program interface is an MS-Excel file where the input data can be easily entered. The outputs are also reported in an MS-Excel format. The computer hardware used is a PC with $2.33 \mathrm{GHz}$ Intel(R) Xeon(R) CPU and $3.25 \mathrm{~GB}$ of RAM. The next section discusses the numerical results of testing the algorithm.

4.3. Shadow Prices. There is a delicate interpretation of the dual variables on the supply side $\left(\beta_{k}, \theta_{k q}\right)$. According to Operational Research (OR) terminology, $\beta_{k}, \theta_{k q}$ (beta and theta) are the shadow prices associated with parking capacity and parking rationing rates. With respect to the objective function, shadow price $\beta_{k}$ represents the value of one extra parking space added to parking zone $k$.

Consider two identical parking zones $\left(k^{\prime}, k^{\prime \prime}\right)$ with only one difference: parking spaces in $k^{\prime}$ are covered. Therefore it is expected to have $\beta_{k^{\prime}}>\beta_{k^{\prime \prime}}$. Attractive parking zones will be occupied sooner than other parking zones. Drivers compete for use of the attractive parking zones. Hence, as the result of this competition, the shadow price is the price that the market is willing to pay for one additional parking space in the attractive or fully occupied parking zones. Obviously, for underutilized parking zones, there is no competition and the corresponding shadow prices $\beta_{k}$ are zero. Intuitively, the shadow price is the answer to a variety of planning issues such as (i) where is the most serious parking shortage? Wherever the shadow prices $\beta_{k}$ are maximum. (ii) How many parking spaces are needed? One should add parking spaces until the 
$\beta_{k}$ becomes zero. A similar interpretation is applied to the shadow price of parking rationing $\left(\theta_{k q}\right)$. We will elaborate on the interpretation of shadow prices in Section 5.3.

\section{Numerical Results}

5.1. Preparing the Case Study. A case study consisting of 100 origin zones, 10 parking zones, and 100 destination zones was developed $(|P|=100,|K|=10,|Q|=100)$. The scale of the case study is comparable to a CBD area with 100 entrance roads and 10 different types of parking zones as well as 100 zones which constitute the CBD area. Below, we define and specify the case study so that it can be utilized by other researchers as a benchmark. As discussed before (see Figure 1), there are four sets of inputs: $G_{p q}$, $U_{p k}, C_{k}$, and $F_{k q}$. These inputs are specified stochastically (randomly), in order to avoid any biased results of applying the methodology to the case study. Tables 1 and 2 present the uniform random numbers used to compute the input data. With respect to subsituation made for (19), the exponential format of the parking utility function $\left(U_{p k}\right)$ is defined as follows (It is important to note that this paper basically offers a methodology tailored to sizable networks and the undertaken case study is a benchmark example. The only part that needs calibration is the Logit parking choice model, which is readily available in cities with comprehensive traffic models (including the traffic model of Abu Dhabi [10]). Therefore we considered the Logit models as a given input in our manuscript, i.e., to spare the space for greater detail in discussing the methodology itself.):

$$
U_{p k}=\exp \left(-1 * R_{p U_{p k}} \cdot R_{k U_{p k}}\right)
$$

where $U_{p k}$ is the utility of parking zone $k$ perceived by drivers from origin $p \cdot U_{p k}$ depends on both the driver's preferences and the parking lot characteristics, both of which are represented by random numbers $\left(R_{p U_{p k}} \cdot R_{k U_{p k}}\right)$. Characteristics impacting driver preferences, such as socioeconomic and demographic characteristics, sex, trip purpose, and driving time to reach the parking lot, are all represented by $R_{p U_{p k}}$. Also, $R_{k U_{p k}}$ includes parking characteristics as well as flowdependent factors such as cost, search time to find a parking space at the parking zone, security, and being covered. We could define the case study utility based on a single random term such as $U_{p k}=\exp \left(-1 * R_{p k U_{p k}}\right)$, which must return 10,000 records of $R_{p k U_{p k}}$ to populate the case study. Instead, to define the case study in a concise format which parallels an actual application, we use the product of two random terms for which we reported 100 and 10 records in Tables 1 and 2 . The same rationale is applied in defining the other inputs. To simulate a real situation for the demand $\left(G_{p q}\right)$ and supply sides $\left(C_{k}, F_{k q}\right)$, exponential types of random numbers are utilized which yield a highly unpredictable dataset $[38,39]$. An exponential random number $(x)$ with expected value of $\lambda$ can be simply computed as follows:

$$
x=-\lambda \cdot \ln (R)
$$

where $0 \leq R \leq 1$ is a uniform random number. Now the demand and supply sides are defined as

$$
\begin{aligned}
G_{p q} & =10 \cdot \ln \left(R_{p G_{p q}} \cdot R_{q G_{p q}}\right), \\
C_{k} & =-10000 \cdot \ln \left(R_{k C_{k}}\right), \\
F_{k q} & =-100 \cdot \ln \left(R_{k F k q} \cdot R_{q F k q}\right) .
\end{aligned}
$$

In (24) we assumed 10 cars as the expected demand between origin-destination pairs, but this number will vary depending on two random numbers $\left(R_{p G_{p q}}, R_{q G_{p q}}\right)$ representing the conditions at the origin and the destination. In total, the demand becomes $\sum_{p q} G_{p q}=185,790.55$. In (25), given the size of demand matrix $(100 \times 100)$ with 10 as the expected value of an entry and 10 parking zones, the expected capacity of parking zones should be $E\left(C_{k}\right)=10,000=100 * 100 *$ $10 / 10$ to meet the demand. Also the parking capacity varies across the parking zones due to the random number $R_{k C_{k}}$. In (26), given 10 parking zones with an expected capacity of 10,000 each and 100 destination zones, the expected rates for parking rationing to proceed the demand can be calculated as: $E\left(F_{k q}\right)=100=10,000 * 10 /(10 * 100)$. Similarly, parking rationing rates may vary due to random numbers representing different conditions at both parking zones and destination zones.

To ensure the feasibility of the solution, the constraints set forth by (8) and (13) must be met. Therefore a simple adjustment is made on the computed input rates in (24), (25), and (26) as follows (":=" means "set to"):

$$
\begin{aligned}
C_{k} & :=\frac{C_{k} \cdot \sum_{p q} G_{p q}}{\sum_{k} C_{k}}, \\
F_{k q} & :=\frac{F_{k q} \cdot \sum_{p} G_{p q}}{\sum_{k} F_{k q}}, \\
F_{k q} & :=\frac{F_{k q} \cdot C_{k}}{\sum_{q} F_{k q}} \text { if } \frac{C_{k}}{\sum_{q} F_{k q}}>1 .
\end{aligned}
$$

In (27) and (28) the parking capacity $\left(\sum_{k} C_{k}\right)$ and rates of parking rationing $\left(\sum_{k} F_{k q}\right)$ are balanced to total demand $\left(\sum_{p q} G_{p q}\right)$. In (29) the parking rationing is adjusted up to the capacity of the corresponding parking zone to eliminate the chance of having a bottleneck in the outbound flow. Table 2 indicates the final values for parking capacity and aggregate rates for parking rationing.

5.2. Executing the Algorithm. The algorithm described in Section 4 is applied to the data developed for the case study, above. The stopping criteria is 100 iterations $\left(i_{\max }=100\right)$. As shown in Figure 1, given four sets of input variables $G_{p q}, U_{p k}$, $C_{k}$, and $F_{k q}$, the algorithm yields three sets of output variables which are

(i) $g_{p k q}$, trips which originate at $p$ who park at lot $k$ and walk to destination $q$;

(ii) $b_{k}=e^{-\beta_{k}}$, shadow price of parking zone $k$; 
TABLE 1: Random numbers corresponding to origin-destination $(p, q)$ used to populate the case study.

\begin{tabular}{|c|c|c|c|c|c|c|c|c|c|}
\hline$p$ or $q$ & $R_{p G p q}$ & $R_{q G p q}$ & $R_{q F k q}$ & $R_{p U p k}$ & $p$ or $q$ & $R_{p G p q}$ & $R_{q G p q}$ & $R_{q F k q}$ & $R_{p U p k}$ \\
\hline 1 & 0.856 & 0.312 & 0.412 & 0.577 & 51 & 0.872 & 0.813 & 0.23 & 0.903 \\
\hline 2 & 0.744 & 0.794 & 0.129 & 0.373 & 52 & 0.402 & 0.473 & 0.596 & 0.819 \\
\hline 3 & 0.859 & 0.177 & 0.862 & 0.764 & 53 & 0.502 & 0.287 & 0.349 & 0.364 \\
\hline 4 & 0.519 & 0.173 & 0.104 & 0.733 & 54 & 0.222 & 0.702 & 0.563 & 0.604 \\
\hline 5 & 0.641 & 0.546 & 0.992 & 0.22 & 55 & 0.158 & 0.374 & 0.834 & 0.742 \\
\hline 6 & 0.928 & 0.749 & 0.146 & 0.947 & 56 & 0.94 & 0.829 & 0.488 & 0.818 \\
\hline 7 & 0.06 & 0.487 & 0.437 & 0.905 & 57 & 0.153 & 0.574 & 0.559 & 0.051 \\
\hline 8 & 0.06 & 0.316 & 0.77 & 0.489 & 58 & 0.488 & 0.862 & 0.694 & 0.407 \\
\hline 9 & 0.454 & 0.5 & 0.262 & 0.651 & 59 & 0.403 & 0.477 & 0.883 & 0.202 \\
\hline 10 & 0.492 & 0.495 & 0.935 & 0.155 & 60 & 0.861 & 0.417 & 0.134 & 0.229 \\
\hline 11 & 0.024 & 0.62 & 0.803 & 0.662 & 61 & 0.914 & 0.869 & 0.063 & 0.514 \\
\hline 12 & 0.136 & 0.58 & 0.809 & 0.884 & 62 & 0.642 & 0.37 & 0.014 & 0.097 \\
\hline 13 & 0.035 & 0.243 & 0.529 & 0.461 & 63 & 0.087 & 0.913 & 0.538 & 0.34 \\
\hline 14 & 0.539 & 0.385 & 0.258 & 0.56 & 64 & 0.989 & 0.638 & 0.846 & 0.762 \\
\hline 15 & 0.764 & 0.468 & 0.951 & 0.377 & 65 & 0.032 & 0.74 & 0.436 & 0.849 \\
\hline 16 & 0.886 & 0.436 & 0.7 & 0.045 & 66 & 0.937 & 0.938 & 0.875 & 0.96 \\
\hline 17 & 0.209 & 0.37 & 0.714 & 0.084 & 67 & 0.002 & 0.118 & 0.2 & 0.506 \\
\hline 18 & 0.616 & 0.94 & 0.408 & 0.625 & 68 & 0.543 & 0.347 & 0.31 & 0.571 \\
\hline 19 & 0.624 & 0.206 & 0.929 & 0.823 & 69 & 0.988 & 0.147 & 0.386 & 0.182 \\
\hline 20 & 0.531 & 0.067 & 0.117 & 0.098 & 70 & 0.51 & 0.236 & 0.299 & 0.212 \\
\hline 21 & 0.766 & 0.456 & 0.619 & 0.689 & 71 & 0.743 & 0.025 & 0.881 & 0.989 \\
\hline 22 & 0.196 & 0.129 & 0.486 & 0.578 & 72 & 0.153 & 0.125 & 0.055 & 0.849 \\
\hline 23 & 0.608 & 0.081 & 0.909 & 0.91 & 73 & 0.608 & 0.639 & 0.552 & 0.102 \\
\hline 24 & 0.264 & 0.015 & 0.621 & 0.995 & 74 & 0.079 & 0.232 & 0.12 & 0.587 \\
\hline 25 & 0.982 & 0.49 & 0.184 & 0.618 & 75 & 0.146 & 0.744 & 0.725 & 0.73 \\
\hline 26 & 0.962 & 0.464 & 0.567 & 0.51 & 76 & 0.775 & 0.874 & 0.317 & 0.822 \\
\hline 27 & 0.967 & 0.872 & 0.313 & 0.355 & 77 & 0.715 & 0.869 & 0.855 & 0.655 \\
\hline 28 & 0.914 & 0.08 & 0.002 & 0.663 & 78 & 0.075 & 0.755 & 0.128 & 0.995 \\
\hline 29 & 0.947 & 0.852 & 0.364 & 0.839 & 79 & 0.64 & 0.758 & 0.767 & 0.92 \\
\hline 30 & 0.76 & 0.402 & 0.381 & 0.93 & 80 & 0.407 & 0.663 & 0.382 & 0.483 \\
\hline 31 & 0.396 & 0.783 & 0.541 & 0.457 & 81 & 0.152 & 0.132 & 0.272 & 0.835 \\
\hline 32 & 0.595 & 0.717 & 0.482 & 0.896 & 82 & 0.808 & 0.616 & 0.931 & 0.248 \\
\hline 33 & 0.892 & 0.851 & 0.844 & 0.356 & 83 & 0.621 & 0.446 & 0.049 & 0.589 \\
\hline 34 & 0.319 & 0.214 & 0.387 & 0.307 & 84 & 0.587 & 0.887 & 0.233 & 0.337 \\
\hline 35 & 0.651 & 0.916 & 0.729 & 0.937 & 85 & 0.112 & 0.571 & 0.949 & 0.386 \\
\hline 36 & 0.214 & 0.268 & 0.154 & 0.754 & 86 & 0.861 & 0.602 & 0.267 & 0.32 \\
\hline 37 & 0.297 & 0.432 & 0.569 & 0.187 & 87 & 0.53 & 0.803 & 0.361 & 0.372 \\
\hline 38 & 0.579 & 0.85 & 0.452 & 0.591 & 88 & 0.65 & 0.981 & 0.781 & 0.582 \\
\hline 39 & 0.481 & 0.854 & 0.34 & 0.354 & 89 & 0.125 & 0.473 & 0.019 & 0.339 \\
\hline 40 & 0.657 & 0.323 & 0.325 & 0.556 & 90 & 0.994 & 0.122 & 0.344 & 0.462 \\
\hline 41 & 0.72 & 0.943 & 0.196 & 0.949 & 91 & 0.038 & 0.538 & 0.488 & 0.333 \\
\hline 42 & 0.405 & 0.026 & 0.24 & 0.631 & 92 & 0.709 & 0.989 & 0.606 & 0.517 \\
\hline 43 & 0.8 & 0.468 & 0.169 & 0.451 & 93 & 0.275 & 0.344 & 0.339 & 0.66 \\
\hline 44 & 0.387 & 0.862 & 0.99 & 0.587 & 94 & 0.217 & 0.289 & 0.277 & 0.136 \\
\hline 45 & 0.079 & 0.41 & 0.331 & 0.761 & 95 & 0.139 & 0.324 & 0.898 & 0.915 \\
\hline 46 & 0.856 & 0.451 & 0.183 & 0.936 & 96 & 0.322 & 0.985 & 0.352 & 0.822 \\
\hline 47 & 0.547 & 0.608 & 0.851 & 0.57 & 97 & 0.086 & 0.966 & 0.543 & 0.89 \\
\hline 48 & 0.475 & 0.636 & 0.316 & 0.871 & 98 & 0.803 & 0.474 & 0.246 & 0.884 \\
\hline 49 & 0.901 & 0.932 & 0.925 & 0.231 & 99 & 0.397 & 0.609 & 0.394 & 0.358 \\
\hline 50 & 0.532 & 0.121 & 0.793 & 0.453 & 100 & 0.137 & 0.962 & 0.883 & 0.91 \\
\hline
\end{tabular}


TABLE 2: Random numbers and inputs corresponding to parking zones $(k)$ used to populate the case study, as well as some outputs.

\begin{tabular}{|c|c|c|c|c|c|c|c|c|}
\hline \multirow[b]{2}{*}{$k$} & \multirow[b]{2}{*}{$R_{k C k}$} & \multicolumn{3}{|c|}{ Inputs } & \multirow[b]{2}{*}{ Sum of $F_{k q}$ on $q$} & \multicolumn{3}{|c|}{ Outputs of the last iteration $i_{\max }=100$} \\
\hline & & $R_{k F k q}$ & $R_{k U p k}$ & $\begin{array}{c}C_{k} ; \text { parking } \\
\text { spaces }\end{array}$ & & $b_{k} ;$ shadow price & Error; $\left|C_{k}-G_{k}\right|$ & $G_{k}$; parking load \\
\hline 1 & 0.811 & 0.182 & 0.888 & $2,883.2$ & $24,260.5$ & 0.0084 & 34.11 & $2,917.35$ \\
\hline 2 & 0.269 & 0.86 & 0.047 & $18,092.8$ & $18,092.9$ & 0.6257 & 3.15 & $18,095.94$ \\
\hline 3 & 0.315 & 0.728 & 0.561 & $15,889.2$ & $15,889.3$ & 0.6429 & 6.68 & $15,895.90$ \\
\hline 4 & 0.074 & 0.032 & 0.64 & $35,943.0$ & $41,578.1$ & 0.4165 & 163.91 & $36,106.87$ \\
\hline 5 & 0.135 & 0.736 & 0.577 & $27,585.2$ & $27,585.4$ & 1.0000 & 365.23 & $27,219.99$ \\
\hline 6 & 0.208 & 0.569 & 0.403 & $21,621.3$ & $21,621.4$ & 0.6762 & 6.90 & $21,628.15$ \\
\hline 7 & 0.568 & 0.037 & 0.126 & $7,779.8$ & $40,030.1$ & 0.0146 & 92.06 & $7,871.87$ \\
\hline 8 & 0.367 & 0.786 & 0.541 & $13,812.2$ & $13,812.3$ & 0.5878 & 4.36 & $13,816.60$ \\
\hline 9 & 0.53 & 0.56 & 0.539 & $8,747.0$ & $13,147.8$ & 0.1061 & 40.36 & $8,787.37$ \\
\hline 10 & 0.088 & 0.508 & 0.207 & $33,436.8$ & $33,437.0$ & 0.8763 & 13.70 & $33,450.52$ \\
\hline Total & & & & $185,790.56^{*}$ & $249,454.7$ & & 730.44 & $185,790.55$ \\
\hline
\end{tabular}

${ }^{*}$ Total demand ( $\operatorname{sum}$ of $G_{p q}$ on $p$ and $q$ ) is $185,790.55$.

(iii) $n_{k q}=e^{-\theta_{k q}}$, shadow prices of the parking rationing rates.

It is clear that, given the parking flow $g_{p k q}$, it is easy to calculate $G_{k}$ occupation rates of the parking lots, and the $G_{k q}$ consumption of reserved (rationed) parking: $G_{k}=\sum_{p q} g_{p k q}$, $G_{k q}=\sum_{p} g_{p k q}$. Table 2 shows occupation rates for each parking zone computed for the last iteration along with the shadow prices. Table 3 presents the aggregate gaps between parking occupation rates and capacity $\left(\sum_{k}\left|C_{k}-G_{k}\right|\right)$ as well as between consumption rates and the parking rationing $\left(\sum_{k q}\left|F_{k q}-G_{k q}\right|\right)$ for 100 successive iterations. Consecutive decreases in the gaps in Table 3 indicate the algorithm's convergence behavior. Furthermore, an error index based on the gap between parking capacity and occupation is defined in Table 3 as $\%$ Err $\_k=\sum_{k}\left|C_{k}-G_{k}\right| / \sum_{k} C_{k}$. Figure 2 graphically illustrates rapid decrease of the error index over 100 successive iterations. As shown in Table 3 and Figure 2, after only four iterations and 1.63 minutes, the percent error falls below $5 \%$. While the running time for the entire 100 iterations is 36.15 minutes, one can terminate the process earlier when a satisfactory solution is obtained. For instance, at iteration 35 only after 11.15 minutes, the error index falls below $1 \%$ which is empirically an acceptable accuracy in transportation practices [40].

It is worth noting that the way the case study was populated results in more computation time than would likely be required in an actual application. In reality, not all the parking spaces would be considered by the drivers. For instance, the drivers might consider only the parking zones within 500 meters of their final destinations [2, 22]. One can filter the available parking using such criteria and reduce the case size and computation time dramatically.

5.3. Interpretation of the Algorithm's Outputs. The methodology described in this study is meant to provide insight for planners or managing authorities to address critical parking related challenges. The shadow prices can be used for this

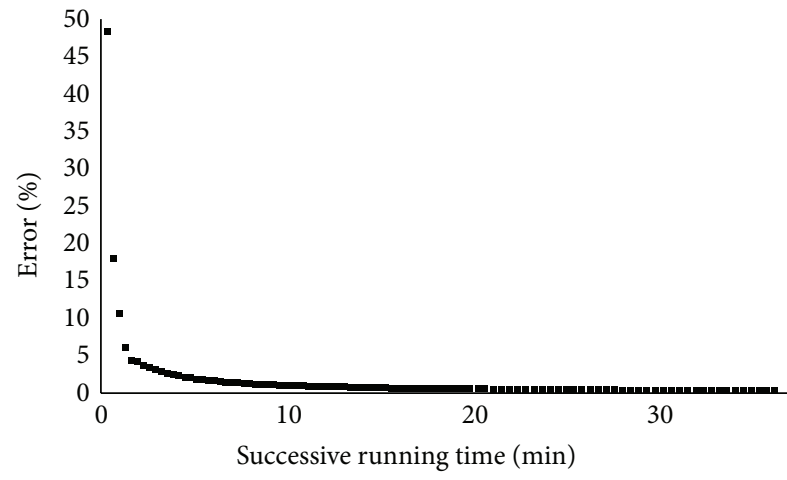

- Error_k $(\%)$

FIGURE 2: Convergence of the algorithm over 100 successive iterations.

purpose because they provide key information. Two sets of shadow prices related to the parking supply side can be interpreted: $b_{k}=e^{-\beta_{k}}$ and $n_{k q}=e^{-\theta_{k q}}$. Table 2 presents shadow prices in exponential form for the parking zones $\left(b_{k}\right)$. It is clear that, after 100 iterations, despite having total parking capacity equal to parking demand, parking zone 5 has not been fully occupied. Zone 5 has a shadow price of $1\left(b_{5}=1\right)$, parking capacity of 27,585, and parking utilization of only 27,220 . For the remaining parking zones we have $0<b_{k}<1$ or $\infty>\beta_{k}>0$. A smaller $b_{k}$ indicates a higher shadow price or beta $\left(\beta_{k}\right)$ which implies that the corresponding parking zone is more attractive for the drivers and the competition to occupy spaces is more intense than other parking zones. This interpretation of the beta is a key insight into answers for a variety of other questions, such as the following. (i) Where is the most important parking shortage? This can be identified as the area in which the beta is the highest. (ii) How many additional parking spaces can be provided? Extra parking spaces can be added to a parking facility whose beta is greater than zero until the beta reaches zero. It is important 
TABLE 3: Convergence result of 100 successive iterations.

\begin{tabular}{|c|c|c|c|c|c|c|c|c|c|}
\hline Itr* $^{*}$ & $\sum_{k}\left|C_{k}-G_{k}\right|$ & $\sum_{k q}\left|F_{k q}-G_{k q}\right|$ & $\%$ Err_k & Time $(\min )$ & Itr & $\sum_{k}\left|C_{k}-G_{k}\right|$ & $\sum_{k q}\left|F_{k q}-G_{k q}\right|$ & \%Err_k & Time (min) \\
\hline 1 & $89,840.1$ & $98,914.2$ & $48.36 \%$ & 0.35 & 51 & $1,364.5$ & $67,151.8$ & $0.73 \%$ & 16.23 \\
\hline 2 & $33,680.5$ & $98,822.6$ & $18.13 \%$ & 0.68 & 52 & $1,337.2$ & $67,105.8$ & $0.72 \%$ & 16.55 \\
\hline 3 & $20,022.0$ & $86,017.7$ & $10.78 \%$ & 1.00 & 53 & $1,323.4$ & $67,058.6$ & $0.71 \%$ & 16.87 \\
\hline 4 & $11,357.4$ & $82,032.7$ & $6.11 \%$ & 1.30 & 54 & $1,296.2$ & $67,014.0$ & $0.70 \%$ & 17.17 \\
\hline 5 & $8,261.8$ & $77,170.0$ & $4.45 \%$ & 1.63 & 55 & $1,283.8$ & $66,968.2$ & $0.69 \%$ & 17.48 \\
\hline 6 & $7,877.1$ & $76,534.6$ & $4.24 \%$ & 1.97 & 56 & $1,258.8$ & $66,925.1$ & $0.68 \%$ & 17.80 \\
\hline 7 & $7,027.6$ & $75,475.1$ & $3.78 \%$ & 2.27 & 57 & $1,245.7$ & $66,882.5$ & $0.67 \%$ & 18.10 \\
\hline 8 & $6,455.0$ & $74,640.9$ & $3.47 \%$ & 2.60 & 58 & $1,222.8$ & $66,844.1$ & $0.66 \%$ & 18.45 \\
\hline 9 & $5,896.8$ & $74,155.3$ & $3.17 \%$ & 2.90 & 59 & $1,210.3$ & $66,805.2$ & $0.65 \%$ & 18.75 \\
\hline 10 & $5,397.9$ & $73,463.9$ & $2.91 \%$ & 3.22 & 60 & $1,190.5$ & $66,768.4$ & $0.64 \%$ & 19.07 \\
\hline 11 & $5,029.7$ & $73,073.7$ & $2.71 \%$ & 3.55 & 61 & $1,176.7$ & $66,731.1$ & $0.63 \%$ & 19.40 \\
\hline 12 & $4,604.6$ & $72,524.4$ & $2.48 \%$ & 3.87 & 62 & $1,158.7$ & $66,695.5$ & $0.62 \%$ & 19.80 \\
\hline 13 & $4,391.9$ & $72,198.4$ & $2.36 \%$ & 4.17 & 63 & $1,144.0$ & $66,660.0$ & $0.62 \%$ & 20.23 \\
\hline 14 & $4,016.2$ & $71,753.5$ & $2.16 \%$ & 4.50 & 64 & $1,127.4$ & $66,627.3$ & $0.61 \%$ & 20.60 \\
\hline 15 & $3,891.1$ & $71,484.1$ & $2.09 \%$ & 4.82 & 65 & $1,111.5$ & $66,593.4$ & $0.60 \%$ & 21.05 \\
\hline 16 & $3,560.8$ & $71,115.7$ & $1.92 \%$ & 5.12 & 66 & $1,096.0$ & $66,560.8$ & $0.59 \%$ & 21.50 \\
\hline 17 & $3,491.7$ & $70,915.1$ & $1.88 \%$ & 5.45 & 67 & $1,080.4$ & $66,527.6$ & $0.58 \%$ & 21.93 \\
\hline 18 & $3,197.4$ & $70,610.5$ & $1.72 \%$ & 5.75 & 68 & $1,065.3$ & $66,495.9$ & $0.57 \%$ & 22.37 \\
\hline 19 & $3,153.5$ & $70,422.0$ & $1.70 \%$ & 6.07 & 69 & $1,050.2$ & $66,465.8$ & $0.57 \%$ & 22.80 \\
\hline 20 & $2,901.4$ & $70,158.3$ & $1.56 \%$ & 6.38 & 70 & $1,037.1$ & $66,437.3$ & $0.56 \%$ & 23.23 \\
\hline 21 & $2,870.6$ & $69,999.2$ & $1.55 \%$ & 6.70 & 71 & $1,024.3$ & $66,408.0$ & $0.55 \%$ & 23.67 \\
\hline 22 & $2,682.0$ & $69,777.4$ & $1.44 \%$ & 7.00 & 72 & $1,011.8$ & $66,379.9$ & $0.54 \%$ & 24.10 \\
\hline 23 & $2,641.8$ & $69,636.3$ & $1.42 \%$ & 7.32 & 73 & 999.3 & $66,351.7$ & $0.54 \%$ & 24.53 \\
\hline 24 & $2,500.8$ & $69,445.6$ & $1.35 \%$ & 7.67 & 74 & 987.2 & $66,325.2$ & $0.53 \%$ & 24.97 \\
\hline 25 & $2,453.9$ & $69,324.1$ & $1.32 \%$ & 7.97 & 75 & 974.9 & $66,299.2$ & $0.52 \%$ & 25.38 \\
\hline 26 & $2,346.6$ & $69,146.4$ & $1.26 \%$ & 8.28 & 76 & 962.7 & $66,274.5$ & $0.52 \%$ & 25.82 \\
\hline 27 & $2,290.3$ & $69,034.3$ & $1.23 \%$ & 8.63 & 77 & 951.0 & $66,250.5$ & $0.51 \%$ & 26.27 \\
\hline 28 & $2,211.5$ & $68,889.0$ & $1.19 \%$ & 8.93 & 78 & 939.9 & $66,227.2$ & $0.51 \%$ & 26.70 \\
\hline 29 & $2,152.9$ & $68,798.3$ & $1.16 \%$ & 9.25 & 79 & 928.7 & $66,204.9$ & $0.50 \%$ & 27.13 \\
\hline 30 & $2,097.5$ & $68,667.9$ & $1.13 \%$ & 9.58 & 80 & 917.5 & $66,182.4$ & $0.49 \%$ & 27.57 \\
\hline 31 & $2,034.9$ & $68,583.5$ & $1.10 \%$ & 9.88 & 81 & 906.2 & $66,160.0$ & $0.49 \%$ & 28.00 \\
\hline 32 & $2,001.4$ & $68,466.1$ & $1.08 \%$ & 10.20 & 82 & 894.9 & $66,137.6$ & $0.48 \%$ & 28.43 \\
\hline 33 & $1,935.2$ & $68,382.5$ & $1.04 \%$ & 10.53 & 83 & 883.8 & $66,115.7$ & $0.48 \%$ & 28.87 \\
\hline 34 & $1,913.9$ & $68,278.0$ & $1.03 \%$ & 10.85 & 84 & 872.7 & $66,093.8$ & $0.47 \%$ & 29.30 \\
\hline 35 & $1,854.2$ & $68,197.6$ & $1.00 \%$ & 11.15 & 85 & 861.8 & $66,072.4$ & $0.46 \%$ & 29.75 \\
\hline 36 & $1,830.5$ & $68,101.6$ & $0.99 \%$ & 11.50 & 86 & 851.0 & $66,051.0$ & $0.46 \%$ & 30.18 \\
\hline 37 & $1,777.3$ & $68,024.0$ & $0.96 \%$ & 11.80 & 87 & 840.3 & $66,030.1$ & $0.45 \%$ & 30.62 \\
\hline 38 & $1,750.8$ & $67,935.6$ & $0.94 \%$ & 12.12 & 88 & 829.9 & $66,010.2$ & $0.45 \%$ & 31.05 \\
\hline 39 & $1,703.2$ & $67,862.8$ & $0.92 \%$ & 12.45 & 89 & 820.2 & $65,991.2$ & $0.44 \%$ & 31.48 \\
\hline 40 & $1,674.6$ & $67,782.4$ & $0.90 \%$ & 12.75 & 90 & 811.1 & $65,972.3$ & $0.44 \%$ & 31.93 \\
\hline 41 & $1,631.6$ & $67,714.8$ & $0.88 \%$ & 13.05 & 91 & 802.1 & $65,953.8$ & $0.43 \%$ & 32.37 \\
\hline 42 & $1,603.3$ & $67,645.8$ & $0.86 \%$ & 13.38 & 92 & 793.3 & $65,935.0$ & $0.43 \%$ & 32.78 \\
\hline 43 & $1,568.2$ & $67,586.0$ & $0.84 \%$ & 13.68 & 93 & 784.5 & $65,917.1$ & $0.42 \%$ & 33.22 \\
\hline 44 & $1,542.1$ & $67,523.9$ & $0.83 \%$ & 14.00 & 94 & 775.9 & $65,899.0$ & $0.42 \%$ & 33.58 \\
\hline 45 & $1,512.3$ & $67,465.3$ & $0.81 \%$ & 14.32 & 95 & 767.3 & $65,881.9$ & $0.41 \%$ & 34.03 \\
\hline 46 & $1,485.3$ & $67,407.9$ & $0.80 \%$ & 14.65 & 96 & 759.1 & $65,865.5$ & $0.41 \%$ & 34.48 \\
\hline 47 & $1,459.4$ & $67,351.6$ & $0.79 \%$ & 14.97 & 97 & 751.6 & $65,850.8$ & $0.40 \%$ & 34.90 \\
\hline 48 & $1,430.6$ & $67,297.6$ & $0.77 \%$ & 15.28 & 98 & 744.6 & $65,836.1$ & $0.40 \%$ & 35.32 \\
\hline 49 & $1,408.1$ & $67,247.3$ & $0.76 \%$ & 15.60 & 99 & 737.5 & $65,821.6$ & $0.40 \%$ & 35.73 \\
\hline 50 & $1,380.6$ & $67,200.2$ & $\mathbf{0 . 7 4} \%$ & 15.92 & 100 & $730.4^{* *}$ & $65,806.7^{* *}$ & $0.39 \%$ & 36.15 \\
\hline
\end{tabular}

*Itr: iteration number; $C_{k}$ and $G_{k}$ : capacity and occupation of parking zone " $k$." $F_{k q}$ and $G_{k q}$ are parking rationing and ration consumption of parking " $k$ " for destination " $q$ "; \% $\%$ rr $\_k=\sum_{k}\left|C_{k}-G_{k}\right| / \sum_{k} C_{k}$.

${ }^{* *}$ Target values for $\sum_{k}\left|C_{k}-G_{k}\right|$ and $\sum_{k q}\left|F_{k q}-G_{k q}\right|$ are 0.01 and $63,664.13$, respectively. 
to note that any change in the supply side of an equilibrated transport system must be made by due diligence due to Braess Paradox [41-43]. (iii) Alternatively, location attractiveness can be adjusted through changing parking zone attractiveness characteristics. For example fees can be managed to balance demand among the parking locations. What is a fair parking fee? The parking fees fed into the Logit parking choice model can be adjusted until the betas for the parking facilities are equalized. This represents a condition where all parking is valued based on its relative value to drivers. (iv) Given an underutilized on-street parking facility, how many parking spaces can be reclaimed for other uses such as green spaces or to create additional roadway capacity? One can reclaim parking spaces until the beta becomes nonzero. (v) Is the city's parking system operating efficiently? If the betas across all the parking facilities are equal, then the system is operating efficiently. The degree to which the betas are unequal indicates the extent of the system's inefficiency. Betas greater than zero indicate a parking shortage. Betas equal to zero mean that there is parking surplus. (vi) Finally, the magnitude of the betas can represent the difficulty of searching for and finding a parking space. Bagloee et al. [10] suggested a convex and nondecreasing function of beta for parking search time to be considered in the parking utility functions. It is similar to what Lam et al. [25] and Tsai and Chu [44] suggest.

Similarly, with respect to the shadow price of parking rationing $\left(\theta_{k q}\right.$ or theta): (i) parking spaces have been reserved for various parking permit holders, neighborhood businesses, or various parking durations (rationed). Is the current rationing system efficient? The degree to which the rationing is efficient can be evaluated by how close to equal thetas are. (ii) How many parking spaces can be reserved for various purposes? The number of reserved parking spaces can be increased as long as the theta for both reserved and nonreserved parking spaces is equal. (iii) What is a fair charge for reserved parking? Reserved parking fees can be raised until the theta for both reserved and nonreserved spaces become even. (iv) Zoning authorities are beginning to shift away from a philosophy of requiring a minimum number of parking spaces for development based solely on land use. They are beginning to consider development location and the other existing parking supply [45]. What is the appropriate parking requirement for a new development? The development should provide as many parking spaces as it takes to result in a zero theta.

\section{Summary and Conclusions}

We developed a model for heterogeneous parking planning that addresses a variety of deficiencies identified in previous studies. The parking choices are considered within the structure of a Logit model, taking advantage of available datasets and rich literature. A mathematical programming problem is introduced to explicitly consider parking capacities and parking rationing constraints. Introduction of parking rationing along with other constraints is a unique aspect of this study. Consideration of parking rationing is intended to cover real life situations including private parking, reserved parking, different parking duration (short term or long term demand), and VIP and disabled parking. A solution algorithm using Successive Coordinate Descent was developed for the Logitbased mathematical programming. The algorithm was tested on an artificial but real-sized and challenging CBD case. The results show the algorithm's convergence.

The algorithm's output includes shadow prices for parking capacity and parking rationing constraints. The shadow prices contain important information which is a key to addressing a variety of parking issues, such as the location of parking shortages, identification of fair parking charges, and how many parking spaces can be dedicated to reserved parking.

This study addresses some shortcomings in the current state of parking modeling. Nonetheless it opens the door to additional study topics. The impacts of parking shortages on departure time have been echoed in the literature. As such consideration of changes in departure times in the parking choices and traffic assignment is a worthwhile investigation. In the same spirit, it would also be interesting to extend the methodology to accommodate dynamic changes in parking demand to create a real-time model. (The dynamic changes in the parking has been set as part of future works. The dynamic aspects of transport modeling can be viewed under Dynamic Traffic Assignment (DTA), which is still an evolving as well as daunting subject. We here at Monash University have embarked on developing the DTA for the city of Melbourne. Hence we are mindful of the complexity of the dynamic features. Therefore it is safe to say that when it comes to parking modeling, the literature first needs to establish a solid ground based on macro parking modeling. Once it is achieved, then, other extensions such as dynamic changes can be added. This paper is an attempt for the first phase, i.e., a macro parking modeling, which is strongly felt missing in the literature.) While the numerical test showed that the methodology is able to address large-size cases, the application to real datasets has yet to be addressed.

\section{Conflict of Interests}

The authors declare that there is no conflict of interests regarding the publication of this paper.

\section{References}

[1] H. Yang, W. Liu, X. Wang, and X. Zhang, "On the morning commute problem with bottleneck congestion and parking space constraints," Transportation Research B: Methodological, vol. 58, pp. 106-118, 2013.

[2] P. Coppola, "A joint model of mode/parking choice with elastic parking demand," in Transportation Planning, pp. 85104, Springer, Berlin, Germany, 2002.

[3] G. N. Bifulco, "A stochastic user equilibrium assignment model for the evaluation of parking policies," European Journal of Operational Research, vol. 71, no. 2, pp. 269-287, 1993.

[4] Z. S. Qian, F. E. Xiao, and H. M. Zhang, "The economics of parking provision for the morning commute," Transportation Research A: Policy and Practice, vol. 45, no. 9, pp. 861-879, 2011.

[5] W. Liu, H. Yang, and Y. Yin, "Expirable parking reservations for managing morning commute with parking space constraints," 
Transportation Research Part C: Emerging Technologies, vol. 44, pp. 185-201, 2014.

[6] W. Liu, H. Yang, Y. Yin, and F. Zhang, "A novel permit scheme for managing parking competition and bottleneck congestion," Transportation Research C: Emerging Technologies, vol. 44, pp. 265-281, 2014.

[7] H. Yang and X. Wang, "Managing network mobility with tradable credits," Transportation Research Part B: Methodological, vol. 45, no. 3, pp. 580-594, 2011.

[8] X. Zhang, H. Yang, and H.-J. Huang, "Improving travel efficiency by parking permits distribution and trading," Transportation Research Part B: Methodological, vol. 45, no. 7, pp. 1018-1034, 2011.

[9] V. L. Makarov and A. M. Rubinov, Mathematical Theory of Economic Dynamics and Equilibria, Springer Science \& Business Media, 2012.

[10] S. A. Bagloee, M. Asadi, and L. Richardson, "Methodology for parking modeling and pricing in traffic impact studies," Transportation Research Record, vol. 2319, pp. 1-12, 2012.

[11] R. Arnott and E. Inci, "An integrated model of downtown parking and traffic congestion," Journal of Urban Economics, vol. 60, no. 3, pp. 418-442, 2006.

[12] R. Arnott and J. Rowse, "Modeling parking," Journal of Urban Economics, vol. 45, no. 1, pp. 97-124, 1999.

[13] M. Florian and M. Los, "Determining intermediate origin-destination matrices for the analysis of composite mode trips," Transportation Research Part B: Methodological, vol. 13, no. 2, pp. 91-103, 1979.

[14] M. Florian and M. Los, "Impact of the supply of parking spaces on parking lot choice," Transportation Research B, vol. 14, no. 1-2, pp. 155-163, 1980.

[15] M. Hudson and N. Raha, "A city-wide, capacity-constrained parking choice model," in Proceedings of the 2010 European Transport Conference, Glasgow, UK, November 2010.

[16] Z.-C. Li, H.-J. Huang, W. H. K. Lam, and S. C. Wong, "A model for evaluation of transport policies in multimodal networks with road and parking capacity constraints," Journal of Mathematical Modelling and Algorithms, vol. 6, no. 2, pp. 239257, 2007.

[17] P. Sattayhatewa and R. L. Smith Jr., "Development of parking choice models for special events," Transportation Research Record, vol. 1858, pp. 31-38, 2003.

[18] D. A. Hensher and J. King, "Parking demand and responsiveness to supply, pricing and location in the Sydney central business district," Transportation Research A: Policy and Practice, vol. 35, no. 3, pp. 177-196, 2001.

[19] S. Hess and J. W. Polak, Mixed Logit Modelling of Parking Type Choice Behaviour Transportation Statistics (77-102), JD Ross Publishing, 2009.

[20] J. D. Hunt and S. Teply, "A nested logit model of parking location choice," Transportation Research Part B, vol. 27, no. 4, pp. 253265, 1993.

[21] Y. Shiftan and R. Burd-Eden, "Modeling response to parking policy," Transportation Research Record, vol. 1765, pp. 27-34, 2001.

[22] H. Tatsumi, "Modeling of parking lot choice behavior for traffic simulation," Journal of the Eastern Asia Society for Transportation Studies, vol. 5, pp. 2077-2091, 2003.

[23] D. Van der Goot, "A model to describe the choice of parking places," Transportation Research A: General, vol. 16, no. 2, pp. 109-115, 1982.
[24] W. Young, "Modeling parking," in Handbook of Transport Modelling, D. A. Hensher and K. J. Button, Eds., Elsevier, Amsterdam, The Netherlands, 2000.

[25] W. H. K. Lam, Z.-C. Li, H.-J. Huang, and S. C. Wong, "Modeling time-dependent travel choice problems in road networks with multiple user classes and multiple parking facilities," Transportation Research Part B: Methodological, vol. 40, no. 5, pp. 368-395, 2006.

[26] K. Martens and I. Benenson, "Evaluating urban parking policies with agent-based model of driver parking behavior," Transportation Research Record, vol. 2046, pp. 37-44, 2008.

[27] R. Petiot, "Parking enforcement and travel demand management," Transport Policy, vol. 11, no. 4, pp. 399-411, 2004.

[28] T. Larsson and M. Patriksson, "An augmented lagrangean dual algorithm for link capacity side constrained traffic assignment problems," Transportation Research B, vol. 29, no. 6, pp. 433-455, 1995.

[29] T. Larsson and M. Patriksson, "Side constrained traffic equilibrium models-analysis, computation and applications," Transportation Research Part B: Methodological, vol. 33, no. 4, pp. 233264, 1999.

[30] J. G. Wardrop, "Road paper. Some theoretical aspects of road traffic research," Proceedings of the Institution of Civil Engineers, vol. 1, no. 3, pp. 325-362, 1952.

[31] Z. Li, H. Huang, H. K. L. William, and S. Wong, "Optimization of time-varying parking charges and parking supply in networks with multiple user classes and multiple parking facilities," Tsinghua Science \& Technology, vol. 12, pp. 167-177, 2007.

[32] X. Zhang, H.-J. Huang, and H. M. Zhang, "Integrated daily commuting patterns and optimal road tolls and parking fees in a linear city," Transportation Research B: Methodological, vol. 42, no. 1, pp. 38-56, 2008.

[33] Z. S. Qian, F. E. Xiao, and H. M. Zhang, "Managing morning commute traffic with parking," Transportation Research Part B: Methodological, vol. 46, no. 7, pp. 894-916, 2012.

[34] K. Dieussaert, K. Aerts, T. Steenberghen, S. Maerivoet, and K. Spitaels, "SUSTAPARK: an agent-based model for simulating parking search," in Proceedings of the AGILE International Conference on Geographic Information Science, Hannover, Germany, 2009.

[35] J. de Dios Ortuzar and L. G. Willumsen, Modelling Transport, Wiley, 1994.

[36] H. Spiess, A Logit Parking Choice Model with Explicit Capacities, EMME/2 Support Center, Aegerten, Switzerland, 1996.

[37] D. G. Luenberger and Y. Ye, Linear and Nonlinear Programming, vol. 116, Springer, New York, NY, USA, 2008.

[38] S. A. Bagloee and C. G. Reddick, "A logit model for budget allocation subject to multi budget sources," International Journal of Strategic Decision Sciences, vol. 2, no. 3, pp. 1-17, 2011.

[39] L. M. Leemis and S. K. Park, Discrete-Event Simulation: A First Course, Pearson Prentice Hall, Upper Saddle River, NJ, USA, 2006.

[40] INRO, EMME3, INRO, Québec, Canada, 3.2 edition, 2007.

[41] S. A. Bagloee, A. Ceder, M. Tavana, and C. Bozic, "A heuristic methodology to tackle the Braess Paradox detecting problem tailored for real road networks," Transportmetrica A: Transport Science, vol. 10, no. 5, pp. 437-456, 2014.

[42] D. Braess, "Über ein Paradoxon aus der Verkehrsplanung," Unternehmensforschung, vol. 12, pp. 258-268, 1968.

[43] D. Braess, A. Nagurney, and T. Wakolbinger, "On a paradox of traffic planning," Transportation Science, vol. 39, no. 4, pp. 446450, 2005. 
[44] M.-T. Tsai and C.-P. Chu, "Evaluating parking reservation policy in urban areas: an environmental perspective," Transportation Research D: Transport and Environment, vol. 17, no. 2, pp. 145148, 2012.

[45] IBI-Group, Review of The City of Toronto Zoning By-Law Parking Standards for Places of Worship, IBI-Group, Toronto, Canada, 2009. 


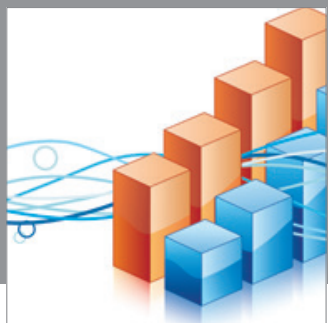

Advances in

Operations Research

mansans

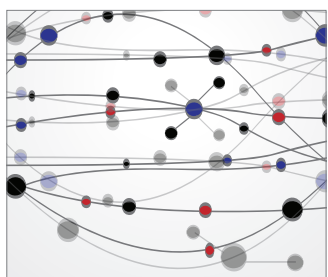

The Scientific World Journal
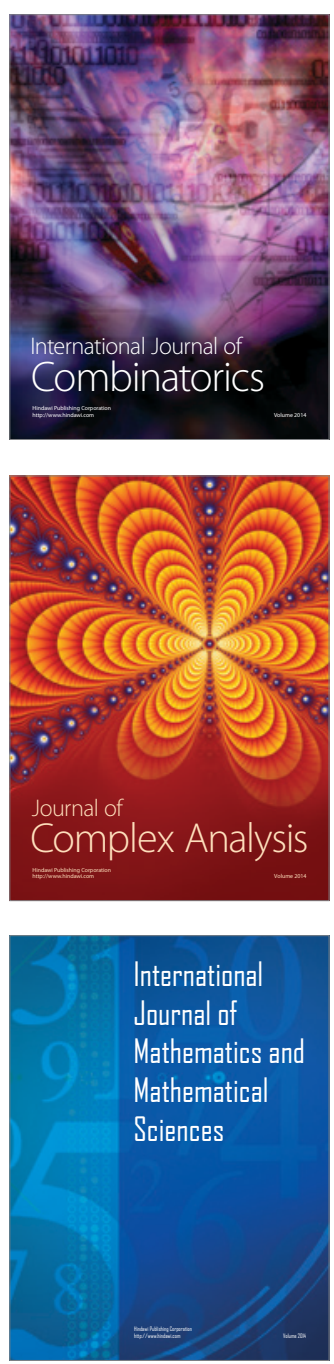
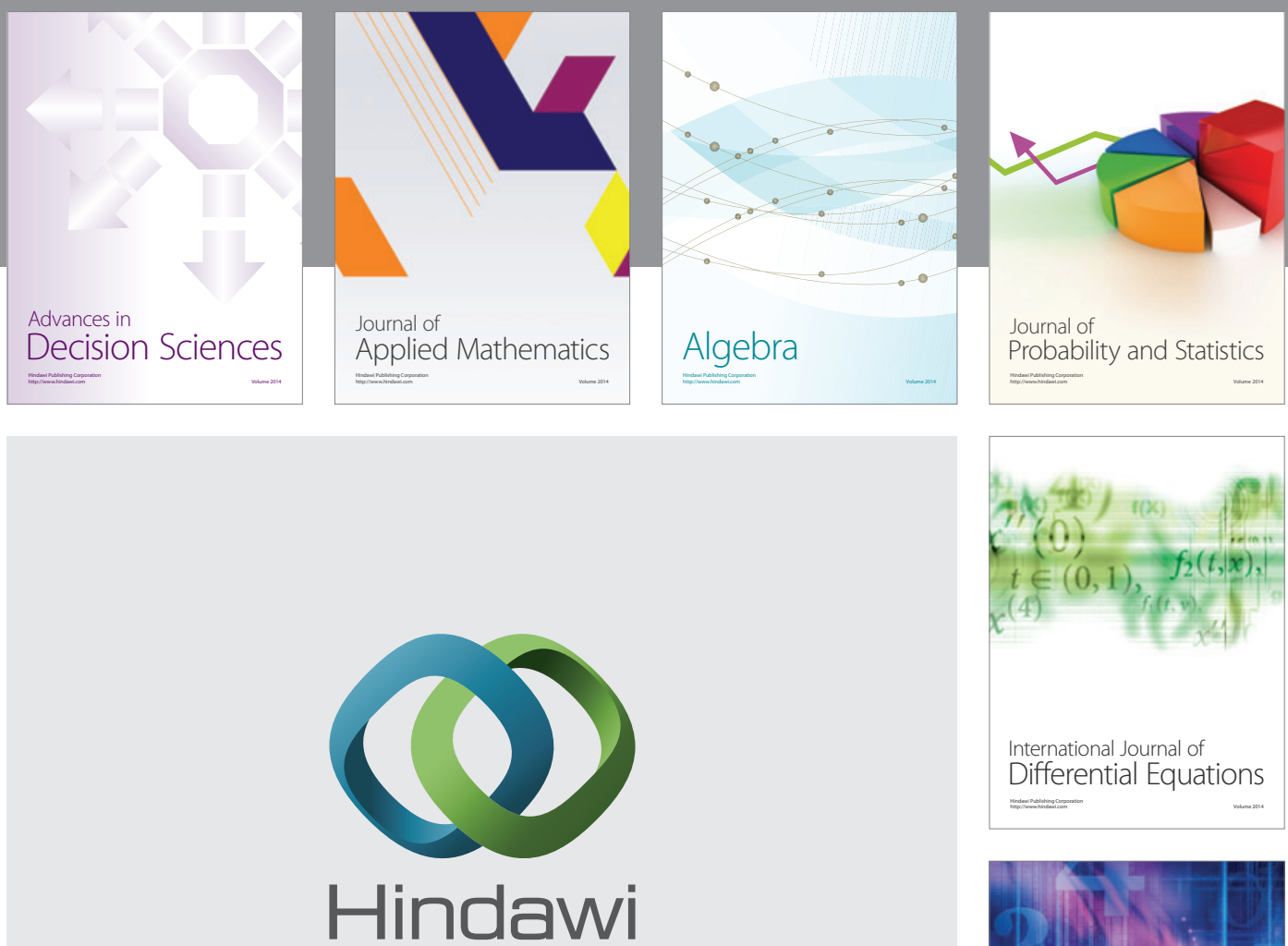

Submit your manuscripts at http://www.hindawi.com
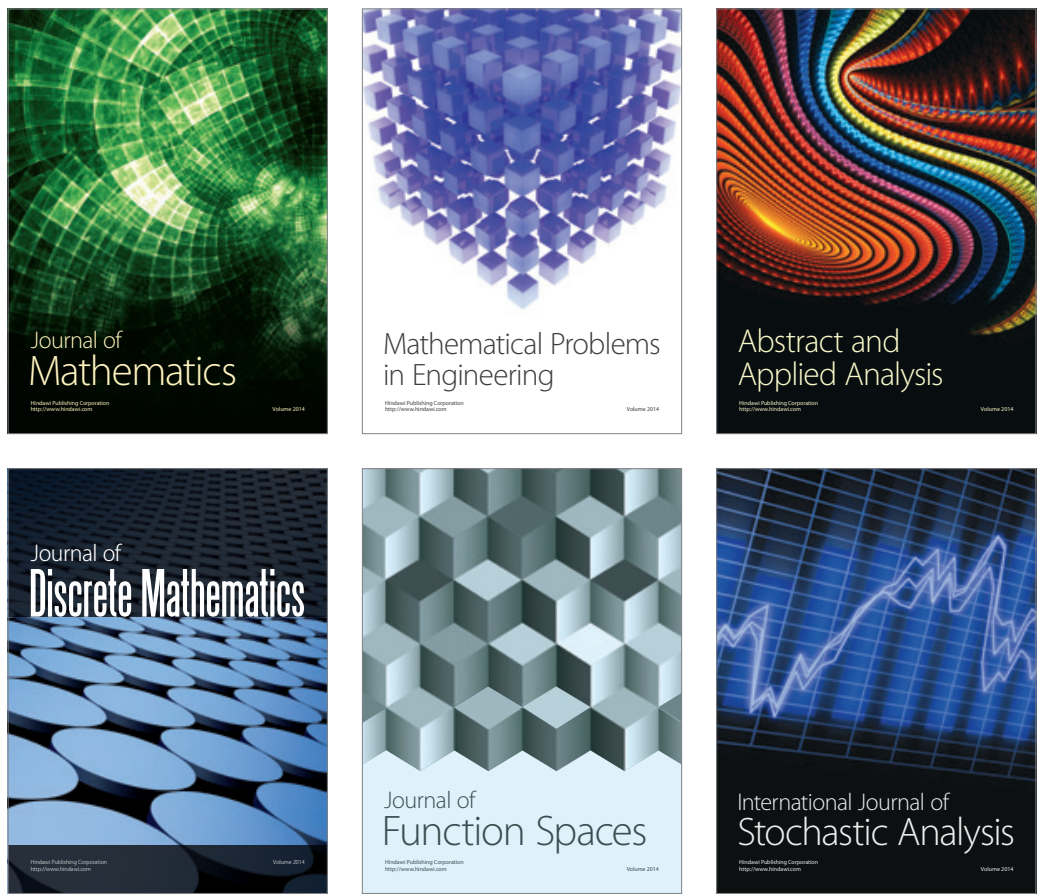

Journal of

Function Spaces

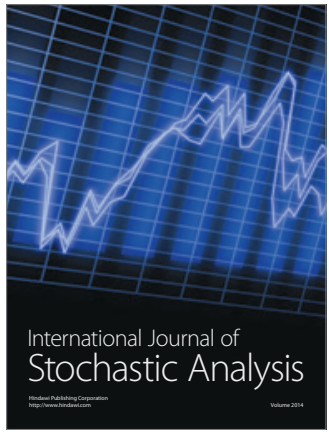

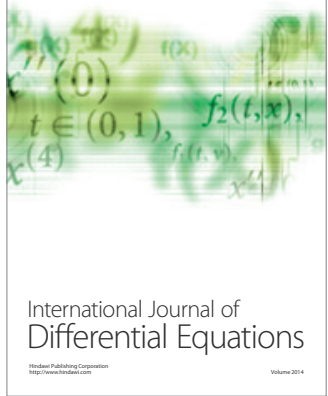
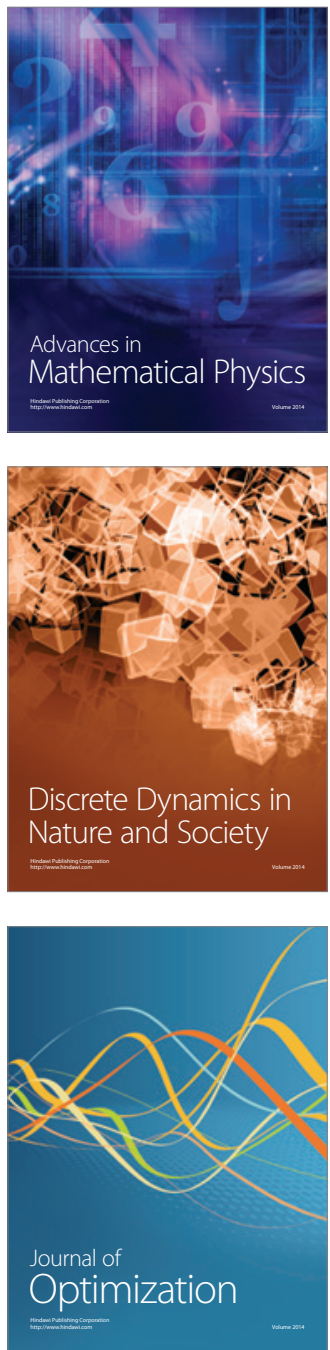